\title{
Existential inquiry: Psychotherapy for crises of demoralization
}

\author{
James L. Griffith, MD \\ Professor of Psychiatry and Neurology, \\ Interim Chair and Director, Psychiatry \\ Residency Program, The George \\ Washington University School of Medicine, \\ Washington, DC
}

USA

\begin{abstract}
Background and Objectives: Existential inquiry is a focal psychotherapy tailored to address crises of demoralization. Demoralization refers to the helplessness, despair, and subjective incompetence that people feel when perceiving themselves to be failing their own or others' expectations for coping with adversity.

Methods: Existential inquiry revives a demoralized person's capacity for coping by eliciting accounts for how the person has sustained hope, communion with others, purpose, agency, commitment, courage, and gratitude when threatened by losses, traumas, or insecurities. Existential questions reveal emotional postures of vulnerability and resilience. They ask both how a person has been impacted by adversities and how he or she has prevailed against them. Existential inquiry rebuilds morale by mobilizing emotional postures of resilience that are grounded in core identities: What are my deep desires and commitments? To whom am I accountable? Who do I know myself to be, or wish to be?

Results: Clinical vignettes illustrate how these questions can open conversations that rebuild morale.

Conclusions: Existential inquiry can serve as an effective brief psychotherapy for countering demoralization.
\end{abstract}

Received: 10 October 2012

Revised: 30 November 2012

Accepted: 19 December 2012 


\section{Introduction}

Most people experience demoralization at some time in their lives. Demoralization refers to the "various degrees of helplessness, hopelessness, confusion, and subjective incompetence" that people feel when sensing that they are failing their own or other's expectations for coping with life's adversities ${ }^{1}$. Much like grief, demoralization can be a normal response to sorrows and struggles that happen in everyday life $^{2}$. The demands of a medical illness, a job loss, or a ruptured relationship are common precipitants for demoralization. Demoralization also can be a consequence of physical violence or social injustice -stigmatization, discrimination, intimidation, or exploitation. Demoralized people rightly feel that their problem lies in their circumstances, not their mental state. Psychotherapy for demoralization thus needs to maintain a focus on the demoralized person's point of concern- the moment-tomoment experience of feeling cornered, living under the shadow of threat, standing with back against the wall.

\section{Existential questions}

Existential questions inquire how a person responds to threats, losses, and insecurities in daily life ${ }^{3-5}$. Existential questions usually are felt to be normalizing, rather than pathologizing, since they ask about adversities that all people, including the clinician, frequently face. "What kept you from giving up?... In your darkest moments, what did you rely upon in order to keep going?... Who did you know would be waiting for you?" Such existential questions ask how a person answers adversity. As Primo Levi observed inside the Auschwitz death camp: "Every human being possesses a reserve of strength whose extent is unknown to him, be it large, small, or nonexistent, and only through extreme adversity can we evaluate it"6.

\section{Existential questions reveal emotional postures of vulnerability and resilience}

An existential posture is the readying of one's being to respond to adversity ${ }^{7}$. An existential posture describes one's intentional stance towards an anticipated future. It connects this intentional state with readiness for action. For clinical purposes, existential postures can be grouped into existential postures of resilience that prepare someone to embrace adversity assertively, and existential postures of vulnerability that prepare someone to withdraw or submit.

Table 1

Existential Postures of Vulnerability and Resilience

\begin{tabular}{ll} 
Vulnerability & Resilience \\
\hline Confusion & Coherence \\
Isolation & Communion \\
Despair & Hope \\
Helplessness & Agency \\
Meaninglessness & Purpose \\
Indifference & Commitment \\
Cowardice & Courage \\
Resentment & Gratitude \\
\hline
\end{tabular}

These existential themes do not of course make an exhaustive list, nor would these be necessarily the most important one's for a particular individual's life. Those listed, however, are some commonly encountered when struggling with medical or psychiatric illnesses. 


\section{Hope versus despair}

Willard was a 64 year old man, suicidal and facing mandatory retirement at his next birthday. "I don't want to be alive at 65". Single, he lived alone and had little social life. For 45 years, his life had revolved around his work, and his relationships were those of the office and the projects he shared with colleagues. Beyond 65, he saw only emptiness. A threemonth brief psychotherapy was largely organized around the question, "Over the years, what has kept alive within you a sense that life can be worth living?" Despite a harsh childhood and long stretches of adult loneliness, he in fact had found enlivening moments when playing sports or volunteering in community service activities. Examining these moments led to his volunteering as an accountant for a community agency that responded to families in financial distress. He began providing consultations to couples and families facing bankruptcy or home foreclosure, helping them re-organize and get fresh footing financially. At age 66, he wrote, "These are the best years of my life." The steps of his brief psychotherapy began with envisioning a desired future, planning pathways towards it, and shifting from passive withdrawal to active engagement with new possibilities.

Hope is created by locating a desired future and taking steps towards $i^{8-11}$. Its counterpart, despair, represents resignation and the relinquishing of a desired future ${ }^{5}$. For patients with medical or psychiatric disorders, despair can pose a greater threat to survival than the disease itself ${ }^{12}$.

Certain questions can open conversations that help patients mobilize hope:

- When did you last feel hopeful? What was that like?

- Which people in your life most help you to stay hopeful?
- When times are hard, what keeps hope alive?

- Who have you known in your life who would not be surprised to see you staying hopeful amidst adversity? What did this person know about you that others may not have known? ${ }^{13}$.

\section{Communion versus isolation}

Janice looked frozen. "How will I pay these loans? I looked at their web site. No one returned my calls. I've got these forms I don't know what to do with".

"As I listen, it stands out to me how alone you are feeling," the therapist commented.

Janice nodded. Her eyes began to tear.

"With whom do you talk when you feel overwhelmed?" the therapist asked.

"My grandmother, but she had a stroke," Janice responded. She told how her grandmother had been the only person in her life with whom she confided openly, without embarrassment, when she felt she was a failure and her life a mess. She felt that her grandmother understood her. Since the stroke, her grandmother had been too impaired to communicate.

The therapist then asked questions about others in her life and who felt some commitment to her. Of these, who understood financial matters and who had resources and might want to help? As the conversation unfolded, a half dozen other family and friends were identified, none of who had been aware of her distress. Janice and the therapist discussed how there are different kinds of trustworthy relationships- some confiding, others providing a sense of security, others available for 
advice or practical help, with few relationships expected to serve all three roles. Janice left with a plan to contact family members who had knowledge and resources to help but had not been those to whom she usually turned for emotional support.

Communion is the felt presence of a trustworthy person. Its counterpart, isolation, is a resigned acceptance that there will be no one there. Medical or psychiatric illness often presses an awareness of who is, or is not, available as a supportive presence. Communion differs from "family", "friends", or even "social support". One can in fact feel deeply lonely when surrounded by people. Certain questions identify relationships that count for communion:

- When did you last feel the close presence of someone who cares for you?

- Who knows what you are going through? To whom do you turn when you need help?

- With whom do you feel most comforted when you are hurting?

- In whose presence do you most feel a bodily sense of peace?

- As you go through this illness, how do you stay connected to people who matter in your life?

- Towards whom do you most freely express love?

\section{Agency versus helplessness}

Elizabeth was a young woman who arrived at an initial psychotherapy session feeling helpless and defeated. "I'm empty... I feel nothing." Her symptoms of depression had so worried her parents and friends that they had coerced her into a psychiatric evaluation that Elizabeth viewed as pointless. "If this psychotherapy were to be successful, what might then happen in your future that is not happening now?" the psychotherapist asked. "I freeze when I think about the future," she responded. Questions about her past then revealed how she had survived emotionally intact, despite a childhood in a dangerous neighborhood where other children were preyed upon. She had survived despite the absence of reliable parents who might have looked out for her or protected her. It was evident that she had been both streetsmart, perceptive, and willful, enough to evade danger and escape serious trauma. When the earlier question was asked a second time: "If this psychotherapy were to be successful, what might then happen in your future that is not happening now?", she could now think of an answer- she would want a group of trusted friends and a career about which she felt commitment and passion. Psychotherapy then proceeded towards these dual objectives. The inquiry about her survival as a child mobilized her sense of personal agency in the present.

Agency is acting in the expectation that one's actions can make a meaningful difference. Helplessness is acting- or not actingwith an expectation that one's actions make no difference. Often medical and psychiatric illnesses erode a sense of agency. Reflective questions can be asked that help a person mobilize a sense of agency, following Eric Cassell's maxim that "there is never a time when nothing can be done"14. Such questions include:

- When was a time when you knew that you were managing your life well, despite problems?

- What should I know about you as a person that is not a part of your illness? 
- Who helps you to stay strong despite the challenges you face?

- How have you managed to keep these problems from taking total control of your life?

\section{Psychotherapeutic strategy underlying existential inquiry}

Existential Inquiry is most indicated while a person feels demoralized and buffeted by threats, uncertainties, and fears- often compounded by shame and guilt from negative self-judgments. Whether to persevere or to capitulate feels uncertain. A sense of subjective incompetence is often strong.

A demoralized person's capacities for focused attention and executive functions, such as organizing, prioritizing, and problem-solving, can be disrupted by intense emotions. In a clinical session, empathy and emotional attunement can be employed to temper arousal so that dialogue and reflection can occur ${ }^{7}$. A psychotherapist's first move thus should be that of compassionate witnessing to listen, understand, and validate the person's experience $^{15,16}$. Asking someone who feels no hope, "How do you keep hope alive?" can evoke rage by its breach of empathy. The same question can be experienced as empathic, however, after a psychotherapist has first conveyed safety and concern.

After an empathic connection has been established, a sampling of different existential questions can be offered as probes, noting which ones appear to resonate with the person's sense of conflict and struggle. Some persons naturally turn inwardly towards individual strengths and resources. "What gets you through your worst days? What keeps you from giving up?" are questions that res- onate. Others naturally turn towards relationships and draw strength from their families, friends, and relational worlds ${ }^{11,16,17}$, "Who understands what you are going through? Who can you count on? What matters most about the days to come?" A clinician's task is to listen for a demoralized person's style of coping, then to focus the dialogue accordingly.

\section{Conclusion}

Existential inquiry is crisis psychotherapy. Existential questions revive the strengths of a demoralized person. Well-placed existential questions often do go quickly to the heart of an experience of adversity. Along different planes of a person's life story, they ask how hardship or loss has impacted a person's life and how the person responded. They help a demoralized person to articulate deeply felt identities that can revive motivation to strive and confidence that choices can make differences that matter.

This moral reasoning is anchored in core identities: "What are my deep desires and commitments? To whom am I accountable? Who do I know myself to be, or wish to be?" The psychotherapist stands as moral witness to a demoralized person's life, as one who acknowledges and affirms the person's deliberations, decisions, and actions as meritorious responses to life's harsh circumstances.

\section{References}

1. Frank JD, Frank JB. Persuasion and healing: A Comparative study of psychotherapy, third edition. Baltimore: Johns Hopkins University Press; 1991. 
2. de Figueiredo JM. Depression and demoralization: Phenomenological differences and research perspectives. Compr Psychiatry 1993; 34: 308-311.

3. Griffith JL. Religion that heals, religion that harms. New York: Guilford Press; 2010.

4. Griffith JL, Dsouza A. Demoralization and hope in clinical psychiatry and psychotherapy. In: Alarcón RD, Frank JB, editors. The Psychotherapy of hope: The legacy of persuasion and healing. Baltimore: Johns Hopkins University Press; 2011.

5. Griffith JL, Gaby L. Brief psychotherapy at the bedside: Countering demoralization from medical illness. Psychosomatics 2005; 46: 109-116.

6. Levi P. Survival in Auschwitz. New York: Simon \& Schuster; 1958/1996.

7. Griffith JL, Griffith ME. The body speaks: Therapeutic dialogues for mind-body problems. New York: Basic Books; 1994.

8. Snyder CR. Hypothesis: There is hope. In: Snyder CR, editor. Handbook of hope: Theory, measures, \& applications. San Diego: Academic Press; 2000. p. 3-21.

9. Snyder CR. Genesis: The birth and growth of hope. In: Snyder CR, editor. Handbook of hope: Theory, measures, \& applications. San Diego: Academic Press; 2000. p. 25-57.

10. Snyder CR, Taylor JD. Hope as a common factor across psychotherapy approaches: A lesson from Dodo's Verdict. In: Snyder CR, ed. Handbook of hope: Theory, measures, \& applications. San Diego: Academic Press; 2000. p. 89-108.
11. Weingarten K. Reasonable hope: Construct, clinical applications, and supports. Fam Proc 2010; 49: 5-25.

12. Harris JC, DeAngelis CD. The power of hope. JAMA 2008; 300: 2919-2920.

13. White M. Re-authoring lives: Interviews and essays. Adelaide, South Australia: Dulwich Centre Publications; 1995.

14. Cassell EJ. The nature of suffering and the goals of medicine. New York: Oxford University Press; 1991.

15. Weingarten K. Common shock: Witnessing violence every day- How we are harmed, how we can heal. New York: Dutton Press; 2003.

16. Weingarten K. Hope in a time of global despair. In: Flaskas C, McCarthy I, Sheehan J, editors. Hope and despair in narrative and family therapy. New York: Routledge; 2007. p. 13-23.

17. Pulleyblank Coffey E. Blowing on Embers. Lumina Press; 2007.

Corresponding author: James L. Griffith, MD Dept. of Psychiatry and Behavioral Sciences 2120 L Street, NW Suite 600

Washington, DC 20037

USA

Phone: (202) 741-2879

Fax: (202) 741-2891

E-mail: jgriffith@mfa.gwu.edu 